\title{
The onset of data-driven mental archeology
}

\section{Sidarta Ribeiro*}

Laboratory of Memory, Sleep and Dreams, Brain Institute, Federal University of Rio Grande do Norte, Natal, Brazil

*Correspondence: sidartaribeiro@neuro.ufrn.br

Edited by:

Sidney A. Simon, Duke University, USA

Reviewed by:

Hao Zhang, Duke University Medical Center, USA

Keywords: mind, self concept, semantic holism, Julian Jaynes, semantic distance, bronze age

\section{A commentary on}

A quantitative philology of introspection by Diuk, C. G., Slezak, D. F., Raskovsky, I., Sigman, M., and Cecchi, G. A. (2012). Front Integr. Neurosci. 6:80. doi: 10.3389/fnint.2012.00080

How did human consciousness arise, in comparison with that of apes? This question has motivated many hypotheses, from psychoanalysis (Freud, 1939) and literature (Bloom, 1999) to evolutionary psychology (Dennett, 1997; Tomasello, 2014). One of the most provocative is that of Julian Jaynes (1976), who understood the question as pertaining to the cultural evolution of introspection during the first millennium BC, known as Axial Age (Jaspers, 1953). Based on ancient texts, Jaynes postulated that our current awareness began with memories of commands uttered by clan chiefs, which allowed for sustained work throughout the day even in the chief's absence. When chiefs died the memories of their voices reverberated in the remaining subjects, and this occurred more strongly in dreams than in waking, due to the absence of sensory interference. Humans evolved a bicameral mind in which part of the activity dealt with the present to perform actions, while the other part dealt with past and future to produce auditory hallucinations perceived as external commands.

Over millennia, people with such mental organization left the caves to build cities and pyramids, as societies with hundreds of thousands members led by a few who heard the voices of dead ancestors turned gods. Eventually there were too many mouths to feed, the empires collapsed, and the voices became mute.
Texts spanning several centuries before 1000 BC reflect this divine silence, as the mental separation between gods and people gradually dissolved. The bicameral person who heard voices gave place to the unicameral individual in whom the self-representation uses its vast mnemonic repertoire not to hallucinate, but to imagine plans. For contemporary mentality the incessant voices of our internal dialog are ours only, not from other entities. Those who today are still split in mental compartments would be psychotic.

For many years this shrewd hypothesis seemed untestable. Corollaries such as the right lateralization of auditory hallucinations were dismissed as too simplisticalthough schizophrenic patients present less language lateralization (Sommer et al., 2001). Yet, the investigation by Diuk et al. (2012) represents a pioneering successful attempt to test Jaynes' theory in a quantitative manner. The authors assessed dozens of Judeo-Christian and GrecoRoman texts from up to the second century CE, as well contemporary Google n-grams, to calculate semantic distances between the reference word "introspection" and all the words in these texts. Cleverly, "introspection" is actually absent from these ancient texts, serving as an "invisible" probe. Semantic distances were evaluated by Latent Semantic Analysis, a high-dimensional model in which the semantic similitude between words is proportional to their co-occurrence in texts with coherent topics (Deerwester et al., 1990; Landauer and Dumais, 1997). The approach goes well beyond the mere counting of word occurrence in a corpus, actually measuring how much the concept of introspection is represented in each text in a "distributed semantic sense," in accordance with the semantic holism (Frege, 1884, 1980; Quine, 1951; Wittgenstein, 1953, 1967; Davidson, 1967) that became mainstream in artificial intelligence (AI) and machine learning (Cancho and Sole, 2001; Sigman and Cecchi, 2002).

The results were remarkable. In Judeo-Christian texts, similitude to introspection increased monotonically over time, with a big change in slope from the Old to the New Testaments. In Greco-Roman texts, comprising 53 authors from Homer to Julius Cesar, a more complex dynamics appeared, with increases in similitude to introspection through periods of cultural development, and decreases during periods of cultural decadence. Contemporary texts showed overall increase, with periods of decline prior to and during the two World Wars. As Jaynes would have predicted, the rise and fall of entire societies seems to be paralleled by increases and decreases in introspection, respectively.

Diuk et al. show that the evolution of mental life can be quantified from the cultural record, opening a whole new avenue of hypothesis testing for Jaynes' theory. While it is impossible to prove that pre-Axial people "heard" the voices of the gods, the findings suggest new ways of studying historical and contemporary texts. In particular, the probing of ancient texts with words like "dream," "god" and "hallucination" has great potential to test Jaynesian concepts.

The featured study lends supports to the notion that consciousness is a social construct in constant flux. Quoting senior author Guillermo Cecchi, "it is 
not just the "trending topics," but the entire cognitive make-up that changes over time, indicating that culture coevolves with available cognitive states, and what is socially considered dysfunction can be tested in a more quantitative way." Indeed, computer science tools are now being applied to psychology and psychiatry (Gottschalk and Bechtel, 2005; Strous et al., 2009; Cabana et al., 2011; Cohen and Elvevåg, 2014; Valle-Lisboa et al., 2014). Graph-theoretical analysis of speech from psychotic patients leads to accurate differential diagnosis of schizophrenia and bipolar disorder type I (Mota et al., 2012, 2014). Semantic analysis is likely to yield even better classification of psychopathological speech symptoms, as indicated by the successful discrimination of mental states induced by psychoactive drugs (Bedi et al., 2014).

The quantification of behavior and the availability of big data create new opportunities in neuroscience research. For instance, there are now many more tools to study the interplay between language, literacy, introspection and lateralization. The featured study opens especially useful paths for the recent boom in the decoding of neural activity, through which abstract concepts can be directly measured (Kay et al., 2008; Mitchell et al., 2008; Horikawa et al., 2013). Cortical semantic representations were recently found to be warped by attention in a holistic manner (Çukur et al., 2013).

More speculatively, the featured study suggests a more intimate relationship between $\mathrm{AI}$ and neuroscience, i.e., $\mathrm{AI}$ as a tool used to understand the brain and the mind, and not just to mimic the mind. Given the brain's complexity, this may be the only way forward. Without an objective way to model and quantify meaning, no deep understanding of the mind will be possible. A bold step in this direction is precisely what the discoveries by Diuk, Slezak and collaborators contribute.

\section{ACKNOWLEDGMENTS}

Support obtained from FAPERN/CNPq PRONEM 003/2011, and FAPESP Research, Innovation and Dissemination Center for Neuromathematics (grant
\#2013/07699-0, São Paulo Research Foundation). The author thanks N. B. Mota for fruitful discussions, A. Karla for administrative help, and D. Koshiyama for library support.

\section{REFERENCES}

Bedi, G., Cecchi, G. A., Slezak, D. F., Carrillo, F., Sigman, M., and de Wit, H. (2014). A window into the intoxicated mind? speech as an index of psychoactive drug effects. Neuropsychopharmacology. doi: 10.1038/npp.2014.80. [Epub ahead of print].

Bloom, H. (1999). Shakespeare: The Invention of the Human. New York, NY: Riverhead Books.

Cabana, A., Valle-Lisboa, J. C., Elvevag, B., and Mizraji, E. (2011). Detecting order-disorder transitions in discourse: implications for schizophrenia. Schizophr. Res. 131, 157-164. doi: 10.1016/j.schres.2011.04.026

Cancho, R. F. I., and Sole, R. V. (2001). The small world of human language. Proc. R. Soc. Lond. B 268, 2261-2265. doi: 10.1098/rspb.2001.1800

Cohen, A. S., and Elvevåg, B. (2014). Automated computerized analysis of speech in psychiatric disorders. Curr. Opin. Psychiatry. 27, 203-209. doi: 10.1097/YCO.0000000000000056

Çukur, T., Nishimoto, S., Huth, A. G., and Gallant, J. L. (2013). Attention during natural vision warps semantic representation across the human brain. Nat. Neurosci. 16, 763-770. doi: 10.1038/ nn.3381

Davidson, D. (1967). Truth and meaning. Synthese 17, 304-323. doi: 10.1007/BF00485035

Deerwester, S., Dumais, S. T., Furnas, G. W., Landauer, T. K., and Harshman, R. (1990). Indexing by latent semantic analysis. J. Am. Soc. Inf. Sci. 41, 391-407.

Dennett, D. C. (1997). Kinds of Minds: Toward An Understanding of Consciousness. Science Masters Series. New York, NY: BasicBooks.

Diuk, C. G., Slezak, D. F., Raskovsky, I., Sigman, M., and Cecchi, G. A. (2012). A quantitative philology of introspection. Front Integr. Neurosci. 6:80. doi: $10.3389 /$ fnint.2012.00080

Frege, G. $(1884,1980)$ The Foundations of Arithmetic. (Trans. J. L. Austin). 2nd Revised Edn. Evanston, IL: Northwestern University Press. ISBN: 0-81010605-1

Freud, S. (1939). Moses and Monotheism. New York, NY: Vintage Books.

Gottschalk, L. A., and Bechtel, R. J. (2005). Computerized content analysis of speech plus speech recognition in the measurement of neuropsychiatric dimensions. Comput. Methods Programs Biomed. 77, 81-86. doi: 10.1016/j.cmpb.2004.08.002

Horikawa, T., Tamaki, M., Miyawaki, Y., and Kamitani, Y. (2013). Neural decoding of visual imagery during sleep. Science 340, 639-642. doi: 10.1126/science. 1234330

Jaspers, K. (1953). The Origin and Goal of History. New Haven, CT: Yale University Press.

Jaynes, J. (1976). The Origin of Consciousness in the Breakdown of the Bicameral Mind. New York, NY: Mariner Books.

Kay, K. N., Naselaris, T., Prenger, R. J., and Gallant, J. L. (2008). Identifying natural images from human brain activity. Nature 452, 352-355. doi: 10.1038/nature06713

Landauer, T. K., and Dumais, S. T. (1997). A solution to plato's prob- lem: the latent semantic analysis theory of acquisition, induction, and representation of knowledge. Psychol. Rev. 104, 211.

Mitchell, T. M., Shinkareva, S. V., Carlson, A., Chang, K. M., Malave, V. L., Mason, R. A., et al. (2008). Predicting human brain activity associated with the meanings of nouns. Science 320, 1191-1195. doi: 10.1126/science.1152876

Mota, N. B., Vasconcelos, N. A., Lemos, N., Pieretti, A. C., Kinouchi, O., Cecchi, G. A., et al. (2012). Speech graphs provide a quantitative measure of thought disorder in psychosis. PLOS ONE 7:e34928. doi: 10.1371/journal.pone. 0034928

Mota, N. B., Furtado, R., Maia, P. P. C., Copelli, M., and Ribeiro, S. (2014). Graph analysis of dream reports is especially informative about psychosis. Sci. Rep. 4:3691. doi: 10.1038/srep03691

Quine, W. V. (1951). Two dogmas of empiricism. Philos. Rev. 60, 20-43.

Sigman, M., and Cecchi, G. A. (2002). The global organization of the Wordnet lexicon. Proc. Natl. Acad. Sci. U.S.A. 99, 1742-1747. doi: 10.1073/pnas.022341799

Sommer, I., Ramsey, N., Kahn, R. S., Aleman, A., and Bouma, A. (2001). Handedness, language lateralisation and anatomical asymmetry in schizophrenia: meta-analysis. Br. J. Psychiatry 178, 344-351. doi: 10.1192/bjp.178.4.344

Strous, R. D., Koppel, M., Fine, J., Nachliel, S., Shaked, G., and Zivotofsky, A. Z. (2009). Automated characterization and identification of schizophrenia in writing. J. Nerv. Ment. Dis. 197, 585-588. doi: 10.1097/NMD.0b013e3181b09068

Tomasello, M. (2014). A Natural History of Human Thinking. Cambridge, MA: Harvard University Press.

Valle-Lisboa, J. C., Pomi, A., Cabana, A., Elvevåg, B., and Mizraji, E. (2014). A modular approach to language production: models and facts. Cortex 55 , 61-76. doi: 10.1016/j.cortex.2013.02.005

Wittgenstein, L. (1953, 1967). Philosophical Investigations. Oxford: Basil Blackwell.

Conflict of Interest Statement: The author declares that the research was conducted in the absence of any commercial or financial relationships that could be construed as a potential conflict of interest.

Received: 15 May 2014; accepted: 28 July 2014; published online: 13 August 2014.

Citation: Ribeiro S (2014) The onset of data-driven mental archeology. Front. Neurosci. 8:249. doi: 10.3389/ fnins.2014.00249

This article was submitted to the journal Frontiers in Neuroscience.

Copyright () 2014 Ribeiro. This is an open-access article distributed under the terms of the Creative Commons Attribution License (CC BY). The use, distribution or reproduction in other forums is permitted, provided the original author(s) or licensor are credited and that the original publication in this journal is cited, in accordance with accepted academic practice. No use, distribution or reproduction is permitted which does not comply with these terms. 